Original Article

\title{
MITOCHONDRIAL DNA CHARACTERIZATION OF HIGH ROYAL JELLY- PRODUCING HONEYBEES (HYMENOPTERA: APIDAE) IN CHINA
}

\author{
Lian Fei Cao ${ }^{1}$ \\ Huo Qing Zheng² \\ Qi Yan Shu ${ }^{1}$ \\ Fu Liang $\mathrm{Hu}^{2}$ \\ Zi Wei Xu ${ }^{1 *}$ \\ ${ }^{1}$ Institute of Animal Husbandry and Veterinary Science, Zhejiang Academy of Agri- \\ cultural Science \\ ${ }^{2}$ College of Animal Sciences, Zhejiang University \\ *corresponding author: ziweixu_nky@163.com \\ Received: 13 January 2017; accepted: 8 June 2017
}

\begin{abstract}
China is the largest producer and exporter of royal jelly in the world. The high production of royal jelly in China is mainly attributed to a high royal jelly-producing lineage of honeybees (Apis mellifera) (HRJB). However, few studies have been conducted on the genetic characterization of HRJB. In this study, the mitochondrial DNA intergenic region between cytochrome oxidase I and II (COI-COII) and the mitochondrial NADH dehydrogenase subunit 2 sequences (ND2) were determined for $90 \mathrm{HRJB}$ colonies, collected from the regions of China where HRJB originated, and 25 unimproved $A$. m. ligustica colonies from China. COI-COll sequence analysis revealed two mitotypes ( $C 1$ and $C 2 d$ ) in HRJB colonies and one mitotype (C1) in unimproved $A$. m. ligustica colonies. The main mitotype (C1) in HRJB accounted for $93 \%$ of the colonies. Based on ND2 sequences, four and two mitotypes were found in HRJB and unimproved $A$. m. ligustica colonies, respectively. Sequence alignment showed that nucleotides in three positions of the ND2 sequence were different between the main mitotype of HRJB and that of unimproved $A$. m. ligustica. Our study suggested that HRJB was bred from $A$. m. ligustica and possibly had genetic characteristics different from unimproved $A$. m. ligustica.
\end{abstract}

Keywords: A. m. ligustica, COI-COII, HRJB, mitotype, mtDNA, ND2

\section{INTRODUCTION}

Royal jelly is an important functional food in many countries (Ramadan \& Al-Ghamdi, 2012). China is the world's largest producer and exporter of royal jelly with an annual production of 3000-4000 tonnes (ASAC, 2015). The high production of royal jelly in China is mainly attributed to the development of a new lineage of Apis mellifera with high royal-jelly producing performance (high royal-jelly producing honeybees, HRJB) (Cao et al., 2016). From the 1960 s to the 1980s, beekeepers in some regions of China selected $A$. mellifera colonies for high royal jelly production. After semi-controlled and directive breeding for decades, royal jelly production of some colonies was more than ten-fold higher than that of unimproved colonies
(Cao et al., 2016). HRJB was recognized by the Chinese government in the late 1980s and was rapidly introduced to other areas of China, which resulted in a great increase in the production of royal jelly in China (CNCAGR, 2011).

It was believed that HRJB was bred from $A . m$. ligustica on the basis that $A$. m. ligustica was the first subspecies of $A$. mellifera introduced into China, as well as being the most widely-distributed subspecies (Yin et al., 2011; Cao et al., 2016). However, there was a lack of evidence, particularly molecular data, to support any relationship between HRJB and $A$. m. ligustica. Population genetics studies, using malate dehydrogenase locus or microsatellites, showed significant genetic differentiation between HRJB and other unimproved $A$. m. ligustica populations (Sun et al., 2004; Chen et al., 2005), which suggested 
that HRJB might have different genetic characteristics from unimproved $A$. m. ligustica.

Methods based on the analysis of COI-COII sequences in mitochondrial DNA (mtDNA) have been widely used in the determination of honeybee lineages (Magnus, Tripodi, \& Szalanski, 2011; Meixner et al., 2013; Coroian et al., 2014). Six evolutionary lineages ( $A, C, M, O, Y$, and $Z$ ) have been found in $A$. mellifera according to morphometric or molecular studies (Ruttner, 1988; Franck et al., 2001; Alburaki et al., 2013). For example, mitotype $\mathrm{C} 1$ was found in all $A$.m. ligustica colonies as well as in some A.m. carnica (Carniolan honeybee) colonies (Franck et al., 2000a; Sušnik et al., 2004). Moreover, the mtDNA ND2 sequence exhibits a high degree of genetic variability and has been widely used to discriminate different honeybee populations (Arias \& Sheppard, 1996; Franck et al., 2000b). Therefore, in this paper, the mtDNA col-coll and ND2 sequences were determined for $\mathrm{HRJB}$ colonies and unimproved $A$. m. ligustica colonies in China to reveal the relationship between HRJB and $A$. m. ligustica, which will be important for the conservation and further improvement of HRJB.

\section{MATERIAL AND METHODS}

\section{Sample collection}

HRJB colonies from Pinghu, Xiaoshan and ChangxingregionsintheZhejiangProvince, China, where HRJB originated (Fig. 1), were sampled during 2012 and 2013. The three regions are about $100 \mathrm{~km}$ apart. Three HRJB colonies were sampled from each of ten breeders of honeybee queens from each region. Unimproved descendants of an $A$. m. ligustica population, imported into China at the beginning of the $20^{\text {th }}$ century, have been raised for a long time in some areas of China. Different $A$. m. ligustica populations have also been introduced as breeding material into China in recent decades from Italy, the USA and Australia. All these $A$. m. ligustica populations have the standard yield of royal jelly and are preserved in the China National Genebank of

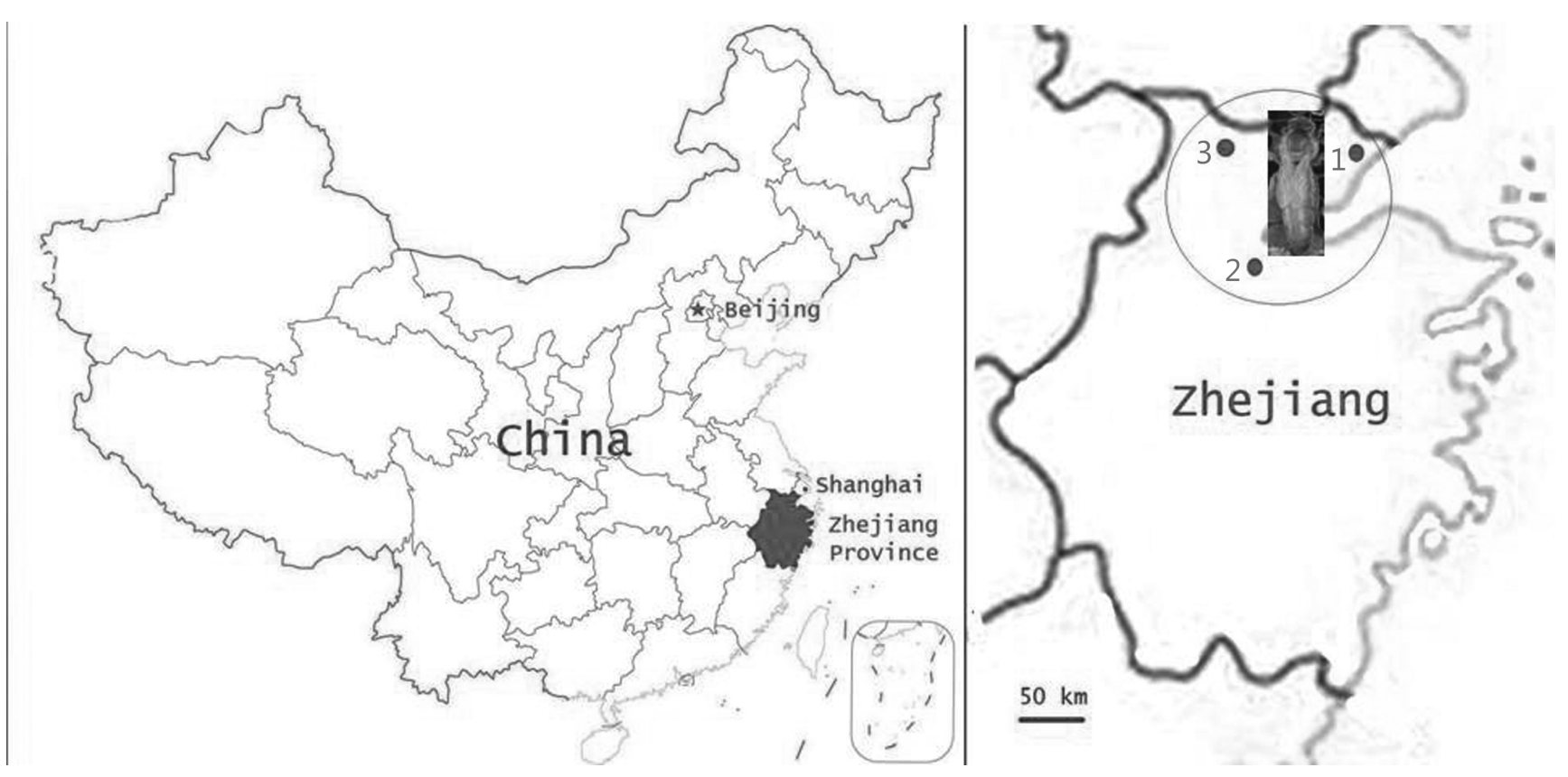

Fig. 1. The shaded area on the left-hand map indicates the main area of distribution of HRJB in China. The area bound by the circle on the right-hand map indicates the original area of distribution of HRJB. The dots denote the HRJB sample collection regions: Pinghu (1), Xiaoshan (2), and Changxing (3). 
Honeybees (Jilin, China). Five colonies from each of the three recently introduced $A$. m. ligustica populations (from Italy, the USA and Australia, respectively) and ten colonies from the early introduced $A$. $m$. ligustica population (at the beginning of the $20^{\text {th }}$ century) were collected at the same time for comparison with HRJB. Therefore, $90 \mathrm{HRJB}$ colonies and 25 unimproved A. m. ligustica colonies were sampled in our study. Thirty adult honey bee workers were preserved in absolute ethanol and stored at $-20^{\circ} \mathrm{C}$ until needed for analysis.

\section{DNA extraction, amplification, and sequencing}

Total DNA was isolated from the thorax of a single worker bee from each colony, using the standard three-step phenol-chloroform method (Sambrook, Fritsch, \& Maniatis, 1989). The mtDNA COI-COII intergenic region was amplified by polymerase chain reaction (PCR), with primers $\mathrm{E2}$ and $\mathrm{H} 2$, according to the protocol described by Cornuet, Garnery, \& Solignac (1991). The mtDNA ND2 sequence was amplified using the primers ILE and L2, as described by Arias et al. (1996). The PCR products were sequenced (Sangon Biotech Co. Ltd., Shanghai, China) in both directions with the primers used for amplification

\section{Sequence alignment and analysis}

DNA sequences were edited using LASERGENE 7.0, aligned by ClustalX 1.81 (Thompson et al., 1997). Mitotypes were first determined using DnaSP 5.10 (Librado \& Rozas, 2009) and then aligned with sequences published in GenBank. Frequencies of mitotypes were calculated for the overall honey bee population and for the populations from each region. Sequence alignment of mitotypes was also performed by ClustalX 1.81.

\section{RESULTS}

Based on the COI-COl/sequences, two mitotypes were found in HRJB colonies (GenBank accession numbers: MF136775 and MF136776). When aligned with sequences published in GenBank, MF136775 was identical to C1 (FJ478010, reported by Franck et al., 2001), while MF136776 was identical to C2d (FJ824584, reported by Muñoz et al., 2009). Mitotypes C1 and C2d had the following overall frequencies: 0.933 and 0.067 , respectively (Tab. 1). Mitotype C1 accounted for $80 \%$ of the colonies from the Pinghu region, whereas the other six colonies belonged to mitotype C2d (present in colonies from four of the ten queen breeders sampled). All the colonies of HRJB honey bees from Xiaoshan and Changxing belonged to mitotype C1. All the unimproved $A$. m. ligustica colonies collected in China belonged to mitotype C1 (Tab. 1).

According to the ND2 sequences, four mitotypes were found in all honeybee colonies (Tab. 2). They were designated as N1-N4 with the GenBank accession numbers MF136771MF136774. In HRJB, N1 was the most common mitotype accounting for $80 \%$ of the colonies.

Mitotypes and distributions based on COI-COll sequences

Table 1

Mitotypes and distributions based on col-coll sequences

\begin{tabular}{|c|c|c|c|c|c|c|}
\hline population & Region & $\begin{array}{l}\text { Geographical } \\
\text { Coordinates }\end{array}$ & Altitude & $\begin{array}{l}\text { Number } \\
\text { of } \\
\text { Colonies }\end{array}$ & $\begin{array}{l}\text { C1a Distri- } \\
\text { bution }\end{array}$ & $\begin{array}{c}\text { C2d Distribu- } \\
\text { tion }\end{array}$ \\
\hline \multirow{3}{*}{$\mathrm{HRJB}$} & Pinghu & $\begin{array}{l}30^{\circ} 45^{\prime} \mathrm{N} \\
121^{\circ} 07^{\prime} \mathrm{E}\end{array}$ & $\sim 3 \mathrm{~m}$ & 30 & 24 & 6 \\
\hline & Xiaoshan & $\begin{array}{l}30^{\circ} 07^{\prime} \mathrm{N} \\
120^{\circ} 24^{\prime} \mathrm{E}\end{array}$ & $\sim 6 \mathrm{~m}$ & 30 & 30 & - \\
\hline & Changxing & $\begin{array}{l}30^{\circ} 57^{\prime} \mathrm{N} \\
119^{\circ} 50^{\prime} \mathrm{E}\end{array}$ & 200 m & 30 & 30 & - \\
\hline $\begin{array}{c}\text { A. m. } \\
\text { ligustica }\end{array}$ & - & - & - & 25 & 25 & - \\
\hline
\end{tabular}




\begin{tabular}{|c|c|c|c|c|c|c|}
\hline \multicolumn{7}{|c|}{ Mitotypes and distributions based on ND2 sequences } \\
\hline population & Region & $\begin{array}{l}\text { Number } \\
\text { of } \\
\text { Colonies }\end{array}$ & $\begin{array}{l}\text { N1 Distribu- } \\
\text { tion }\end{array}$ & $\begin{array}{l}\text { N2 Distribu- } \\
\text { tion }\end{array}$ & $\begin{array}{l}\text { N3 Distribu- } \\
\text { tion }\end{array}$ & $\begin{array}{c}\mathrm{N} 4 \\
\text { Distribution }\end{array}$ \\
\hline \multirow{3}{*}{ HRJB } & Pinghu & 30 & 17 & 6 & 6 & 1 \\
\hline & Xiaoshan & 30 & 29 & - & - & 1 \\
\hline & Changxing & 30 & 26 & - & - & 4 \\
\hline $\begin{array}{c}\text { A. m. } \\
\text { ligustica }\end{array}$ & - & 25 & 1 & - & - & 24 \\
\hline
\end{tabular}

Table 3

Nucleotide differences among mitotypes of ND2 sequences

\begin{tabular}{cccccc}
\hline \multirow{2}{*}{ Mitotype } & \multicolumn{5}{c}{ Nucleotide Position (according to NC_001566) } \\
\cline { 2 - 6 } & 504 & 541 & 685 & 999 & 1015 \\
\hline H1 & C & C & A & T & C \\
H2 & T & C & G & C & C \\
H3 & C & C & A & T & T \\
NC & C & T & G & C & C \\
\hline
\end{tabular}

On the contrary, N4 was the main mitotype in unimproved $A$. m. ligustica colonies accounting for $96 \%$ of these colonies. In the HRJB colonies from the Pinghu region, mitotypes N2 and N3 were present at moderate frequencies (approximately $20 \%$ in each case). Sequence alignment was performed with the four mitotypes derived from the ND2 sequences (nucleotide position according to NC_001566, reported by Crozier \& Crozier, 1993) (Tab. 3). It showed that the nucleotides were different in position 541, 685 and 999 between the main mitotype N1 in $\mathrm{HRJB}$ colonies and the main mitotype $\mathrm{N} 4$ in unimproved non-HRJB A. m. ligustica colonies.

\section{DISCUSSION}

MtDNA sequences have previously been used to analyze molecular diversity and population genetic structures of honey bee populations from different regions, and have proved to be an effective tool (Franck et al., 2000b; Muñoz et al., 2009, 2012). This current study is the first genetic variation study, using primarily mtDNA sequences, conducted on HRJB honey bees from China.

Results of the COI-COII sequence analysis showed that the main mitotype $\mathrm{C} 1$ in HRJB was identical to that in unimproved $A$. $m$. ligustica colonies in China, which suggested that $A . m$. ligustica was probably the founder population of HRJB. Although studies have shown that several A. m. carnica colonies also carried mitotype $\mathrm{C1}$ (Sušnik et al., 2004), A. m. carnica honeybee workers usually have a black body color which is different from the mainly yellow color of HRJB honey bee workers (Our unpubl. data). Furthermore, historical records have shown that $A$. m. ligustica was first introduced into China (CNCAGR, 2011). Zhejiang Province, where HRJB originated and where it is mainly distributed, was one of the areas where beekeepers first began to raise $A$. m. ligustica in China (CNCAGR, 2011). Combining the results from our COI-COII sequence analysis with the morphological characters and relevant historical records, it is likely that HRJB was bred from $A$. m. ligustica. In addition to mtDNA COI-COl/sequences, mtDNA 
ND2 sequences were also used to analyze the molecular genetic diversity of honeybees, and could provide additional useful information (Franck et al., 2000b). In our study, the results based on the COI-COIl sequences identified the possible origin of HRJB honey bees. Furthermore, with the results based on the ND2 sequences three basic differences were found that distinguished HRJB colonies from unimproved $A$. m. ligustica colonies. Therefore, our study may provide a simple method, based on ND2 sequences, for the differentiation of HRJB from unimproved $A$. m. ligustica colonies in China. For example, discrimination between the bases $C$ and $T$ at position 541 of the ND2 sequence could identify $96 \%$ of the unimproved A. m. ligustica colonies and $93 \%$ of HRJB colonies. HRJB colonies from the Pinghu region were noted to have a larger number of mitotypes than those from the other two regions, an observation which should be considered in future conservation strategies. Pinghu, as the center of origin of HRJB, contains a large number of such colonies. The large population size, as well as the longer period of adaptation of honeybees in Pinghu, may help to maintain the high level of genetic diversity. A previous study based on microsatellites had also found that a significant genetic differentiation existed among HRJB populations from different regions (Yin et al., 2011). Although HRJB honeybees exhibit high royal jelly-producing performance, further breeding should be carried out to increase the 10-HDA (10-hydroxy-2-decenoic acid) content of royal jelly and improve the colonies' general resistance to disease (Cao et al., 2016). The heterozygosity among HRJB populations may provide favorable conditions for further selection or breeding.

To summarize, we confirmed that HRJB was probably bred from $A$. m. ligustica, with HRJB also having different genetic characteristics, based on mitochondrial DNA sequences, compared to unimproved $A$. m. ligustica. However, mtDNA can only reflect the maternal origin of HRJB. In the future, additional molecular technologies such as single nucleotide polymorphism (SNP) analysis should be applied to improve our understanding of the genetic characterization of HRJB.

\section{ACKNOWLEDGEMENTS}

We would like to thank Shui-Hua Jin, Guo-Quan Yang and Ru-Min Qiu for their help during sampling. This study was funded by Project 31602014 supported by the National Natural Science Foundation of China, the Science and Technology Department of Zhejiang Province, China (2016C02054-11).

\section{REFERENCES}

Alburaki, M., Bertrand, B., Legout, H., Moulin, S., Alburaki, A., Sheppard, W. S., Garnery, L. (2013). A fifth major genetic group among honeybees revealed in Syria. BMC Genetics, 14(117), 1-10. DOl: 10.1186/1471-2156-14-117

Arias, M. C., \& Sheppard, W. S. (1996). Molecular phylogenetics of honey bee subspecies (Apis mellifera L.) inferred from mitochondrial DNA sequences. Molecular Phylogenetics and Evolution, 5(3), 557-566. DOl: 10.1006/mpev.1996.0050

(ASAC) Apicultural Science Association of China. (2015). China's bee products market review of 2014 and prospect for 2015. ASAC: Beijing [in Chinese].

Cao, L. F., Zheng, H. Q., Pirk, C. W. W., Hu, F. L., Xu, Z. W. (2016). High royal jelly-producing honeybees (Apis mellifera ligustica) (Hymenoptera: Apidae) in China. Journal of Economic Entomology, 109(2), 510-514. DOl: 10.1093/jee/tow013

Chen, S. L., Li, J. K., Zhong, B. X., \& Su, S. K. (2005). Microsatellite analysis of royal jelly producing traits of Italian honeybee (Apis mellifera liguatica). Acta Genetica Sinica, 32(10), 1037-1044.

(CNCAGR) China National Commission of Animal Genetic Resources. (2011). Animal genetic resources in China-Bees. Chinese Agricultural Press: Beijing [in Chinese].

Cornuet, J. M., Garnery, L., \& Solignac, M. (1991). Putative origin and function of the intergenic region between COI and COll of Apis mellifera L. mitochondrial DNA. Genetics, 128(2), 393-403. 


\section{- CAH ET HL. — Mitochondrial DNA characterization of HRJB}

Coroian, C. O., Muñoz, l., Schlüns, E. A., Paniti-Teleky, O. R., Erler, S., Furdui, E. M., ... Moritz, R. F. A. (2014). Climate rather than geography separates two European honeybee subspecies. Molecular Ecology, 23 (9), 2353-2361. DOl: 10.1111/mec.12731

Crozier, R. H., \& Crozier, Y. C. (1993). The mitochondrial genome of the honeybee Apis mellifera - complete sequence and genome organization. Genetics, 133(1), 97-117.

Franck, P., Garnery, L., Solignac, M., \& Cornuet, J. M. (2000a). Molecular confirmation of a fourth lineage in honeybees from the near east. Apidologie, 37(2), 167-180. DOl: 10.1051/apido: 2000114

Franck, P., Garnery, L., Celebrano, G., Solignac, M., Cornuet, J. M. (2000b). Hybrid origins of honeybees from Italy (Apis mellifera ligustica) and Sicily (A. m. sicula). Molecular Ecology, 97), 907-921. Dol: 10.1046/j.1365-294x.2000.00945.x

Franck, P., Garnery, L., Loiseau, A., Oldroyd, B. P., Hepburn, H. R., Solignac, M., Cornuet, J. M. (2001). Genetic diversity of the honeybee in Africa: microsatellite and mitochondrial data. Heredity, 86(4), 420-430. DOl: 10.1046/j.1365-2540.2001.00842.x

Librado, P., \& Rozas, J. (2009). DnaSP v5: a software for comprehensive analysis of DNA polymorphism data. Bioinformatics, 25(11), 1451-1452. DOl: 10.1093/bioinformatics/btp187

Magnus, R. M., Tripodi, A. D., \& Szalanski, A. L. (2011). Mitochondrial DNA diversity of honey bees, Apis mellifera L. (Hymenoptera: Apidae) from queen breeders in the United States. Journal of Apicultural Science, 55(1), 37-46.

Meixner, M. D., Pinto, M. A., Bouga, M., Kryger, P., Ivanova, E., Fuchs, S. (2013). Standard methods for characterising subspecies and ecotypes of Apis mellifera. Journal of Apicultural Research, 52(4), 1-27. DOl: 10.3896/IBRA.1.52.4.05

Muñoz, I., Dall'Olio, R., Lodesani, M., \& Rúa, P. D. L. (2009). Population genetic structure of coastal Croatian honeybees ( Apis mellifera carnica). Apid- ologie, 4066), 617-626. https://DOl.org/10.1051/ apido/2009041

Muñoz, l., Stevanovic, J., Stanimirovic, Z., \& Rúa, P. D. L. (2012). Genetic variation of Apis mellifera from serbia inferred from mitochondrial analysis. Journal of Apicultural Science, 56(1), 59-69. https://DOl. org/10.2478/v10289-012-0007-9

Ramadan, M. F., \& Al-Ghamdi, A. (2012). Bioactive compounds and health-promoting properties of royal jelly: A review. Journal of Functional Foods, 4(1), 39-52. DOl: 10.1016/j.jff.2011.12.007

Ruttner, F. (1988). Biogeography and taxonomy of honey bees. Springer Verlag Press: Berlin.

Sambrook, J., Fritsch, E. F., \& Maniatis, T. (1989). Molecular cloning: a laboratory manual. Cold Spring Harbor Laboratory Press: New York.

Sun, L. X., Chen, Z. Y., Yuan, J. J., \& Xie, J. J. (2004). Genetic variability of $\mathrm{MDH}$ II in four lines of Apis mellifera ligustica. Joural of Zhangzhou Teachers College (Nat. Sci.), 171), 54-59 [in Chinese].

Sušnik, S., Kozmus, P., Poklukar, J., \& Megli, V. (2004). Molecular characterisation of indigenous Apis me/lifera carnica in Slovenia. Apidologie, 35(6), 623-636. DOl: 10.1051/apido: 2004061

Thompson, J. D., Gibson, T. J., Plewniak, F., Jeanmougin, F., Higgins, D. G. (1997). The CLUSTAL_X windows interface: flexible strategies for multiple sequence alignment aided by quality analysis tools. Nucleic Acids Research, 25(24), 4876-4882. DOl: 10.1093/ nar/25.24.4876

Yin, L., Ji, T., Chen, G. H., \& Peng, W. J. (2011). Genetic characterization of three breeds of high royal jelly producing honeybee (Apis mellifera ligustica) in China. African Journal of Agricultural Research, 6(2), 331-337. DOl: 10.5897/AJAR10.850 